\title{
ИНТЕЛЛЕКТУАЛЬНОЕ РАЗВИТИЕ ДЕТЕЙ, ЗАНИМАЮЩИХСЯ ПО ТЕХНОЛОГИИ «МЕНТАЛЬНАЯ АРИФМЕТИКА»
}

\section{Вострецова Н.С.}

Чувашский государственный педагогический университет им. И.Я. Яковлева, г. Чебоксары, Чувашская Республика, Российская Федерация

В статье рассмотрена технология «Ментальная арифметика» для развития детей России (методика Smartykids), описаны результаты корреляционного анализа на констатирующем и контрольном этапах эксперимента.

Ключевые слова: ментальная арифметика; абакус; интеллектуальное развитие детей; дошкольники.

\section{INTELLECTUAL DEVELOPMENT OF CHILDREN, ENGAGED IN TECHNOLOGY "MENTAL ARITHMETIC"}

\section{Vostretsova N.S.}

Chuvash State Pedagogical University named after I.Ya. Yakovleva, Cheboksary, Chuvash Republic, Russian Federation

The article discusses the technology "Mental arithmetic" for the development of children in Russia (Smartykids technique), describes the results of correlation analysis at the ascertaining and control stages of the experiment.

Keywords: mental arithmetic; abacus; intellectual development of children; preschoolers.

«Ментальная арифметика» представляет собой одну из молодых и перспективных технологий в системе образования и развития детей. 
Главным инструментом обучения по технологии «Ментальная арифметика» является абакус (лат. Abacus - доска) - счётная доска. В Китае она называются суаньпань, в Японии - соробан, в России - счёты.

Технология «Ментальная арифметика» пришла в Россию из Японии, где разработана система тренировки интеллекта с помощью абакуса. В 90-е годы ХХ столетия с развитием нейробиологии было выявлено, что работа детей с абакусом может быть использована для тренировки ума в целом. Ученые выяснили, что максимально активно и быстро мозг ребенка развивается в возрасте с 4 до 12 лет, когда вся новая информация быстро усваивается, а знания остаются в памяти на долгие годы. Именно поэтому регулярные занятия и развитие ребенка в этот в период оказывают огромное влияние на его будущее $[1,2]$.

Пользу технологии «Ментальная арифметика» подтверждают данные международных исследований. В Великобритании в 2007 году были проведены исследования среди 3185 детей в возрасте от 7 до 11 лет [6]. В результате систематических занятий дети значительно улучшили показатели не только по математике, но и по другим дисциплинам.

Исследование влияния ментальной арифметики на память детей, проведенное в Китае [7], выявило значительное улучшение визуальной памяти у учеников. В исследовании «Оценка памяти учащихся после курсов ментальной арифметики», проходившем в Индии с 2002 по 2004 гг., приняло участие 50 детей в возрасте от 5 до 12 лет [8]. Благодаря курсу «Ментальная арифметика» у всех детей улучшились зрительная и слуховая память, повысилась концентрация внимания. Американский терапевт Джин Хаустон установила, что во время тренировки также значительно повышаются показатели интеллекта. Очевидно, упражнения ведут к тому, что в мозге образуются новые нервные клетки, что ведет к повышению возможностей нашего интеллекта [5].

По мнению ученых, человеческий мозг имеет огромный потенциал. В первую очередь это касается правого полушария, обе- 
спечивающего характеристики визуальной памяти, воображение и креативность. И этот потенциал практически не используется у большинства людей.

Науке давно известно, что правое и левое полушария нашего мозга выполняют, если так можно выразиться, разные типы умственных работ. Построение логических цепочек, анализ ситуации, математические вычисления выполняет преимущественно левое полушарие, тогда как правое «отвечает» за творчество, воображение и эмоции.

Обучение детей устному счету основано на работе с абакусом в комплексе со следующими приемами и специальными развивающими упражнениями:

1. Использование двух рук. Обучающиеся производят вычисления на счетах сразу двумя руками, что позволяет не только развивать каждое полушарие, но и оптимизировать их взаимодействие.

2. Визуализация. Постепенно реальный счетный инструмент заменяется его невидимым аналогом в детском воображении. Дети представляют числовые примеры не в виде цифровых знаков, а в виде изображений с определенным положением косточек на воображаемых счетах.

3. Пальцематика. Пальчики рук используются даже тогда, когда ребенок начинает считать в уме. С их помощью ребенок передвигает невидимые счетные косточки.

4. Умение управлять своим мозгом. Обучающиеся, которые осваивают устный счет по технологии «Ментальная арифметика» могут одновременно выполнять математические упражнения в уме, совершать действие пальцами рук и использовать свои творческие способности (рисовать, прыгать, танцевать, читать с выражением стихи).

5. На занятиях обязательно используется умственная разминка и упражнения на гармонизацию полушарий мозга.

Руководители и педагоги школ ментальной арифметики в России отмечают, что быстрый счет - это лишь побочный продукт данной технологии, на самом деле она направлена на развитие мозга - причем обоих полушарий в равной степени. 
Нами было проведено исследование с целью определения степени интеллектуального развития детей, обучающихся по технологии «Ментальная арифметика» (методика SmartyKids) в течение семи месяцев в городе Москва. В исследовании приняли участие 19 детей от 6 до 8 лет. В качестве экспресс-диагностики интеллектуальных способностей детей 6-8 лет использовался тест МЭДИС. В него входят следующие субтесты: С3 - словарный запас, ККО - понимание количественных и качественных отношений, ЛМ - логическое мышление, $\mathrm{MC}$ - математические способности. Формирующий этап состоял из 28 занятий (2 часа - каждое занятие) по курсу «Ментальная арифметика», включающих упражнения на абакусе, работа на тренажерах: «Ментальный счет», «Флеш-карты», «Прыгающие числа», «Двойной экран», интеллектуальные разминки, упражнения на гармонизацию обоих полушарий.

На контрольном/констатирующем этапах эксперимента были получены следующие общие результаты: низкий уровень интеллектуального развития - 5/0 человек, средний уровень - 6/6 человек, высокий уровень - 8/13 человек.

В таблице 1 приводятся результаты корреляционного анализа до и после формирующего эксперимента (курс «Ментальная арифметика»). Жирным шрифтом отмечены коэффициенты корреляции с уровнем значимости по двухстороннему критерию 0,05 .

Таблицуа 1.

Корреляционный анализ результатов теста МЭДИС на констатирующем и контрольном этапах эксперимента

\begin{tabular}{|c|c|c|c|c|c|c|c|c|c|}
\hline \multicolumn{4}{|c|}{ Констатирующий этап } & \multicolumn{5}{|c|}{ Контрольный этап } \\
\hline $\begin{array}{c}\text { Тест } \\
\text { МЭДИС }\end{array}$ & СЗ & ККО & ЛМ & МС & $\begin{array}{c}\text { Тест } \\
\text { МЭДИС }\end{array}$ & СЗ & ККО & ЛМ & МС \\
\hline СЗ & $\mathbf{1 , 0 0}$ & $\mathbf{0 , 8 4}$ & 0,31 & $\mathbf{0 , 5 3}$ & С & $\mathbf{1 , 0 0}$ & $-0,14$ & 0,25 & 0,11 \\
\hline ККО & $\mathbf{0 , 8 4}$ & $\mathbf{1 , 0 0}$ & $\mathbf{0 , 5 0}$ & $\mathbf{0 , 6 4}$ & ККО & $-0,14$ & $\mathbf{1 , 0 0}$ & $-0,40$ & $-0,29$ \\
\hline ЛМ & 0,31 & $\mathbf{0 , 5 0}$ & $\mathbf{1 , 0 0}$ & $\mathbf{0 , 6 6}$ & ЛМ & 0,25 & $-0,40$ & $\mathbf{1 , 0 0}$ & $\mathbf{0 , 6 7}$ \\
\hline МС & $\mathbf{0 , 5 3}$ & $\mathbf{0 , 6 4}$ & $\mathbf{0 , 6 6}$ & $\mathbf{1 , 0 0}$ & МС & 0,11 & $-0,29$ & $\mathbf{0 , 6 7}$ & $\mathbf{1 , 0 0}$ \\
\hline
\end{tabular}

Результаты корреляционного анализа показывают, что на констатирующем этапе почти все показатели интеллектуального развития 
детей по разным субтестам методики МЭДИС имеют значимые взаимосвязи. После занятий ментальной арифметикой в течение семи месяцев происходит существенное изменение структуры связей интеллектуальных характеристик: взаимосвязанными остались только логическое мышление (ЛМ) и математические способности (МС) коэффициент корреляции 0,67.

Этот результат подтверждает известный принцип дифференциации-интеграции $[2,3]$. В данном случае - это возможность влияния на структуру когнитивных показателей детей с помощью занятий ментальной арифметикой.

Практика педагогов и отзывы родителей показывают повышение самооценки и улучшение эмоциональной устойчивости детей [4], доказывают, что технология «Ментальная арифметика» весьма полезна и действенна. В результате обучения ребёнок получает следующие навыки:

- быстрого счёта в уме;

- концентрации внимания на решении определённой задачи;

- творческих способностей, фантазии, воображения;

- умения находить разные пути для решения поставленных задач;

- аналитического мышления, логики, системного подхода к любой проблеме.

Кроме того, существенно укрепляется память, дети получают возможность без усилий запоминать большие массивы цифровой, текстовой и зрительной информации. У старших дошкольников к этому прибавляется развитие мелкой моторики пальчиков, что является очень важным для успешного развития интеллектуальных способностей.

Таким образом, технология «Ментальная арифметика» стала одной из ступеней к развитию интеллектуальных способностей. Потенциал мозга, который запускается во время занятий, позволяет воспитать интеллектуального и успешного ребенка, маленького гения, который в будущем способен проявить себя, прекрасно адаптироваться и найти креативный выход из любой ситуации. 


\section{Список литературы}

1. Кирилина Н.Ю., Федорова Т.В. Технология «Ментальная арифметика» в организации образовательной деятельности дошкольников. Из опыта работы // Молодой ученый. 2017. №15.2. С. 89-91. Режим доступа: URL https://moluch.ru/archive/149/41625/ (дата обращения: 15.09.2019).

2. Slavutskaya E.V., Slavutskii L.A. Preadolescent age: the formation of the interconnections in the personality structure. Psikhologicheskie Issledovaniya, 2014, Vol. 7, No. 37, p. 6. http://psystudy.ru

3. Slavutskaya E.V. Slovesno-logicheskoe myshlenie i strukturirovanie lichnostnyh chert $\mathrm{v}$ predpodrostkovom vozraste [Verbal-logical thinking and the structuring of the preadolescents personality traits]. Izvestiya of Saratov University. New Series. Series: Educational Acmeology. Developmental Psychology. 2015. № 4(3), pp. 203-207 (in Russian). DOI: 10.18500/2304-9790-2015-4-3-203-206

4. Славутская Е.В., Вострецова Н.С. Факторный анализ гендерных особенностей эмоциональной сферы и самооценки дошкольников // Казанский педагогический журнал. 2019. № 2 (133). С. 69-73.

5. Центр ментальной арифметики SmartyKids [Электронный pecypc]. Режим доступа: https://vk.com/smartykids

6. Lynn R., Irwing P. (2008) Effect of Abakus trainig on the intelligence of Sudanese children. // Personality and Individual Differences. November 2008, pp. 694-696.

7. Min-Sheng Chen, Chang-Tzu Wang. Effect of mental abacus training on working memory for children. // Journal of the Chinese Institute of Industrial Engineers 09/2011; 28(6), pp. 450-457.

8. The Soroban / Abacus Handbook is (C) 2001-2003 by David Bernazzani Rev 1.0 - March 9, 2003.

\section{References}

1. Kirilina N.Yu., Fedorova T.V. Tekhnologiya «Mental'naya arifmetika» v organizatsii obrazovatel'noy deyatel'nosti doshkol'nikov. Iz opyta raboty// Molodoy uchenyy. 2017. №15.2. S. 89-91. Rezhim dostupa: URL https://moluch.ru/archive/149/41625/ (data obrashcheniya: 15.09.2019). 
2. Slavutskaya E.V., Slavutskii L.A. Preadolescent age: the formation of the in-terconnections in the personality structure. Psikhologicheskie Issledovaniya, 2014, Vol. 7, No. 37, p. 6. http://psystudy.ru

3. Slavutskaya E.V. Slovesno-logicheskoe myshlenie i strukturirovanie lich-nostnyh chert $\mathrm{v}$ predpodrostkovom vozraste [Verbal-logical thinking and the structuring of the preadolescents personality traits]. Izvestiya of Saratov Univer-sity. New Series. Series: Educational Acmeology. Developmental Psychology. 2015. № 4(3). Rr. 203-207 (in Russian). DOI: 10.18500/2304-9790-2015-4-3-203-206

4. Slavutskaya E.V., Vostretsova N.S. Faktornyy analiz gendernykh osoben-nostey emotsional'noy sfery i samootsenki doshkol'nikov // Kazanskiy peda-gogicheskiy zhurnal. 2019. № 2 (133). S. 69-73.

5. Tsentr mental'noy arifmetiki SmartyKids [Elektronnyy resurs]. Rezhim dostupa: https://vk.com/smartykids

6. Lynn R., Irwing P. (2008) Effect of Abakus trainig on the intelligence of Suda-nese children. // Personality and Individual Differences. November 2008, Pages 694-696.

7. Min-Sheng Chen, Chang-Tzu Wang. Effect of mental abacus training on work-ing memory for children. // Journal of the Chinese Institute of Industrial Engi-neers 09/2011; 28(6): Pages 450-457.

8. The Soroban / Abacus Handbook is (C) 2001-2003 by David Bernazzani Rev 1.0 - March 9, 2003. 